\title{
DFT-D2 simulations of water adsorption and dissociation on the low-index surfaces of mackinawite (FeS)
}

Cite as: J. Chem. Phys. 144, 174704 (2016); https://doi.org/10.1063/1.4947588

Submitted: 04 February 2016 . Accepted: 07 April 2016. Published Online: 02 May 2016

N. Y. Dzade, A. Roldan (iD, and N. H. de Leeuw (i)
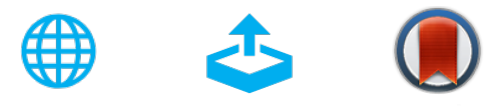

\section{ARTICLES YOU MAY BE INTERESTED IN}

Activation and dissociation of $\mathrm{CO}_{2}$ on the (001), (011), and (111) surfaces of mackinawite (FeS): A dispersion-corrected DFT study

The Journal of Chemical Physics 143, 094703 (2015); https://doi.org/10.1063/1.4929470

Adsorption of methylamine on mackinawite (FES) surfaces: A density functional theory study

The Journal of Chemical Physics 139, 124708 (2013); https://doi.org/10.1063/1.4822040

A consistent and accurate ab initio parametrization of density functional dispersion correction (DFT-D) for the 94 elements $\mathrm{H}-\mathrm{Pu}$

The Journal of Chemical Physics 132, 154104 (2010); https://doi.org/10.1063/1.3382344

\section{Lock-in Amplifiers up to $600 \mathrm{MHz}$}
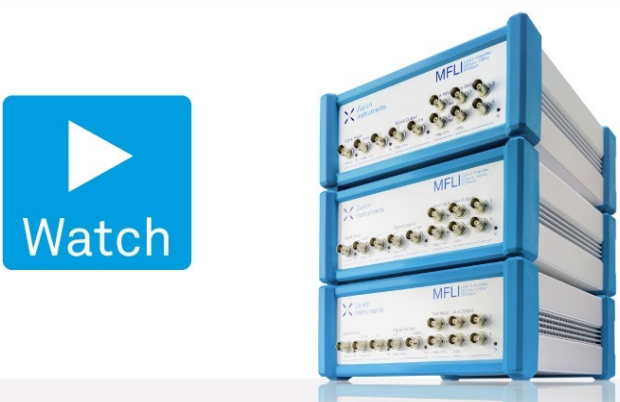


\title{
DFT-D2 simulations of water adsorption and dissociation on the low-index surfaces of mackinawite (FeS)
}

\author{
N. Y. Dzade, ${ }^{1, a)}$ A. Roldan, ${ }^{2}$ and N. H. de Leeuw ${ }^{1,2, b)}$ \\ ${ }^{1}$ Department of Earth Sciences, Utrecht University, Princetonplein 9, 3584 CC Utrecht, The Netherlands \\ ${ }^{2}$ School of Chemistry, Cardiff University, Main Building, Park Place, CF10 3AT Cardiff, United Kingdom
}

(Received 4 February 2016; accepted 7 April 2016; published online 2 May 2016)

\begin{abstract}
The adsorption and dissociation of water on mackinawite (layered FeS) surfaces were studied using dispersion-corrected density functional theory (DFT-D2) calculations. The catalytically active sites for $\mathrm{H}_{2} \mathrm{O}$ and its dissociated products on the $\mathrm{FeS}\{001\},\{011\},\{100\}$, and $\{111\}$ surfaces were determined, and the reaction energetics and kinetics of water dissociation were calculated using the climbing image nudged elastic band technique. Water and its dissociation products are shown to adsorb more strongly onto the least stable FeS $\{111\}$ surface, which presents low-coordinated cations in the surface, and weakest onto the most stable $\mathrm{FeS}\{001\}$ surface. The adsorption energies decrease in the order $\operatorname{FeS}\{111\}>\operatorname{FeS}\{100\}>\operatorname{FeS}\{011\}>\operatorname{FeS}\{001\}$. Consistent with the superior reactivity of the $\mathrm{FeS}\{111\}$ surface towards water and its dissociation products, our calculated thermochemical energies and activation barriers suggest that the water dissociation reaction will take place preferentially on the FeS nanoparticle surface with the $\{111\}$ orientation. These findings improve our understanding of how the different FeS surface structures and the relative stabilities dictate their reactivity towards water adsorption and dissociation. Published by AIP Publishing. [http://dx.doi.org/10.1063/1.4947588]
\end{abstract}

\section{INTRODUCTION}

The reactions that occur at the mineral-water interface are central to all geochemical processes. They affect a wide range of important earth processes, including weathering and soil formation, dissolution of minerals, biomineralization, acid mine drainage, the fate of contaminants, nutrient availability, metal corrosion, and heterogeneous catalysis. ${ }^{1-3}$ Many important industrial catalytic processes also involve the adsorption and dissociation or formation of water molecules at solid surfaces, for example, the water-gas shift reaction and reactions in fuel cells or other electrocatalytic devices. ${ }^{4,5}$ Owing to the particular relevance of the mineral-water interface to geochemical processes and heterogeneous catalysis, considerable research efforts have been dedicated to understanding its properties and there are many catalyst materials currently under investigation to facilitate the water dissociation process. One such class of materials includes transition metal chalcogenide compounds consisting of chalcogen anions (sulfur and oxygen) and transition metal cations. Various experimental studies have reported their synthesis and investigated the properties of transition metal chalcogenides for a broad range of applications, including electronics, optoelectronics, photovoltaics, and photocatalysis. ${ }^{6-10}$

Amongst the transition metal chalcogenides, those formed by iron and sulfur (iron sulfides) are attracting significant attention for potential applications in photovoltaic solar cells, ${ }^{8,11-13}$ solid state batteries, ${ }^{14,15}$ biomedicine, ${ }^{16,17}$ and

\footnotetext{
a)Electronic mail: N.Y.Dzade@uu.nl

b)Electronic mail: deLeeuwN@cardiff.ac.uk
}

heterogeneous catalysis, ${ }^{18-21}$ owing to their low cost, natural abundance, and remarkable electronic and physical properties. Layered iron(II) monosulfide mackinawite (FeS) and greigite $\left(\mathrm{Fe}_{3} \mathrm{~S}_{4}\right)$ are increasingly considered to be the early catalysts for a series of biochemical reactions that occur in hydrothermal systems, making them relevant in origin of life theories. ${ }^{22-26}$ Mackinawite crystallises in the tetragonal structure (Figure 1), with space group P4/nmm. ${ }^{27,28}$ The FeS structure is formed by vertically stacked two-dimensional (2D) layers with strong covalent bonding between $\mathrm{Fe}$ and $\mathrm{S}$ atoms within a given layer and very weak van der Waals ( $\mathrm{vdW}$ ) bonding between the adjacent layers. ${ }^{29}$ Each iron atom is arranged in squareplanar coordination with neighbouring irons, whereas sulphur atoms are positioned in an asymmetric one-sided four-fold coordination with iron. Like other 2D layered materials, for example, $\mathrm{MoS}_{2}$, FeS possesses a high specific surface area ideal for catalysis. $\mathrm{MoS}_{2}$, for instance, is being widely used as an efficient catalyst for hydrodesulphurization, ${ }^{30}$ oxygen reduction, ${ }^{31}$ and hydrogen evolution ${ }^{32,33}$ reactions. It was also demonstrated to have an exceptional performance for water splitting, approaching that of Pt-group metals. ${ }^{34,35}$

The need to study the interaction of water with the low-index surfaces of $\mathrm{FeS}$ is indisputable. The origin of $\mathrm{FeS}$, along with other iron sulfides, is hydrothermal, where water would have been present and may also have been the necessary hydrogen source in $\mathrm{CO}_{2}$ reduction reactions catalysed by $\mathrm{FeS}$. An understanding of the interactions of water with the surfaces of $\mathrm{FeS}$ may also provide detailed insights into the underlying reaction mechanisms of its facile oxidation, ${ }^{36-38}$ which remains a major problem that severely limits the potential applications of these materials. Earlier experimental ${ }^{38-42}$ and theoretical ${ }^{43-45}$ studies of the 
(a)
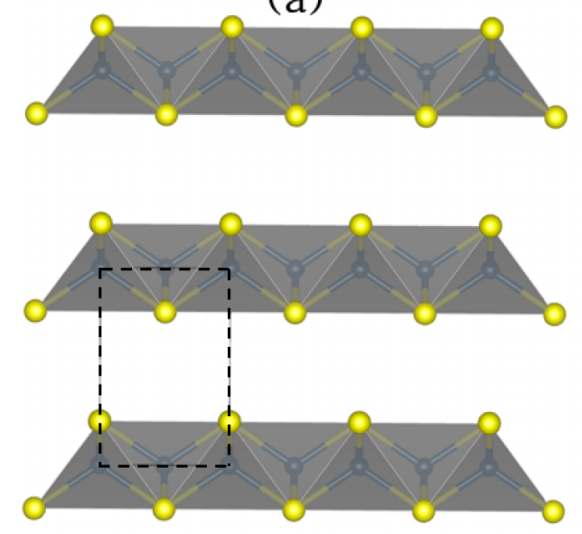

(b)

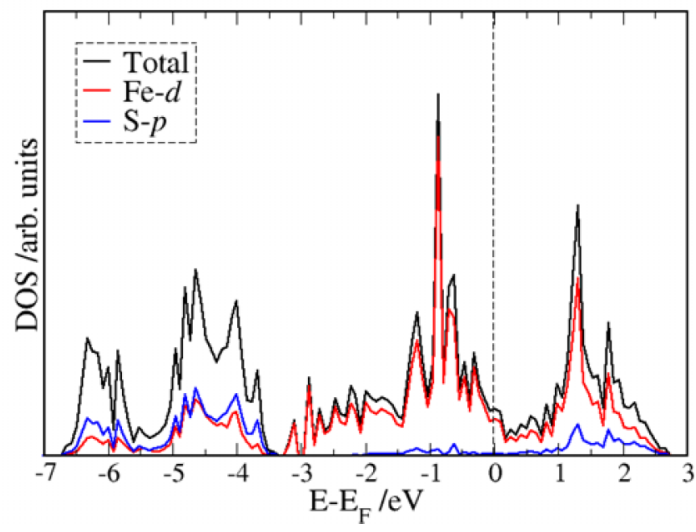

FIG. 1. The layered structure of mackinawite (a), with the tetragonal unit cell highlighted by dash lines. The electronic density of state showing the total and projection on the $\mathrm{Fe} d$-states and $\mathrm{S} p$-states are shown in (b). (Colour scheme: $\mathrm{Fe}=$ grey, $\mathrm{S}=$ yellow.) reaction of iron sulfides with water have focused extensively on the pyrite surfaces. The catalytic dissociation of water on the low-index surfaces of violarite, $\mathrm{FeNi}_{2} \mathrm{~S}_{4}$, has also been reported recently using density functional theory (DFT) methods. ${ }^{46}$ A theoretical understanding of the fundamental adsorption and dissociation processes of water on $\mathrm{FeS}$ surfaces is, however, still lacking, although a detailed understanding of this process and how it is affected by different surface structures is essential for the development of FeS catalysts.

In this paper, we have used first-principles calculations to conduct a comparative investigation of water adsorption and dissociation $\left(\mathrm{H}_{2} \mathrm{O} \rightarrow \mathrm{OH}^{-}+\mathrm{H}^{+}\right)$mechanisms, in terms of thermodynamic stability, active sites, and activation barriers on the $\{001\},\{011\},\{100\}$, and $\{111\}$ surfaces of FeS. First, the geometries and active sites for water adsorption were studied for four surface terminations of FeS. Next, the activation energy barriers for the water dissociation reaction on each surface were determined using the climbing image nudged elastic band (CI-NEB) methodology. The results are expected to aid in identifying which of the four crystallographic surfaces considered in this work is the most efficient for water adsorption and dissociation.

\section{COMPUTATIONAL DETAILS}

The optimized structures were determined using planewave density functional theory (PW-DFT) calculations within the Vienna $A b$ initio Simulation Package (VASP code). ${ }^{47-49}$ The interactions between the valence electrons and the ionic core were described with the projected augmented wave (PAW) method ${ }^{50,51}$ and the electronic exchange-correlation was treated using the Generalized Gradient Approximation (GGA) with the PW91 functional. ${ }^{52,53}$ Long range nonlocal effects such as van der Waals (vdW) forces, which are essential for the accurate description of the interlayer interactions in $\mathrm{FeS},{ }^{19,54}$ were accounted for through the Grimme DFT-D2 functional. ${ }^{55}$ An energy cutoff of $400 \mathrm{eV}$ for the plane-wave basis set was tested to be sufficient to converge the total energy of the bulk FeS and the different surface slabs to within $0.0001 \mathrm{eV}$. The on-site potential, GGA + U, was not considered for these calculations as previous studies using VASP on "FeS" have shown that due to delocalization of the $d$-electrons, considering the $+\mathrm{U}$ correction term provides inadequate structural optimizations. ${ }^{57}$ Geometry optimizations were performed using the conjugate gradient minimization algorithm until the magnitude of the residual Hellman-Feynman force on each relaxed atom reached $0.01 \mathrm{eV} / \AA$. The equilibrium cell parameters for the bulk FeS were obtained using a Monkhorst-Pack ${ }^{56} \mathrm{~K}$-point mesh of $11 \times 11 \times 11$ to sample the Brillouin-zone integrations and all calculations were non-spin polarized. The resulting cell parameters were $a=3.587 \AA, c=4.908 \AA$, and $c / a=1.368 \AA$, which compare closely with those measured experimentally $(a=3.674 \AA$, $c=5.033 \AA$, and $c / a=1.370) .{ }^{33,34}$ The metallic character is also accurately reproduced as shown in Figure 1(b), with the electronic states of the Fe $d$-orbitals dominating the regions around the Fermi level, in agreement with previous DFT results, ${ }^{57-60}$ as well as the experimental results of Vaughan and Ridout. ${ }^{61}$

The $\{001\},\{011\},\{100\}$, and $\{111\}$ families of surfaces, which are the dominant growth surfaces expressed in the morphology of the FeS nanocrystals, ${ }^{19,62}$ were created using the METADISE code ${ }^{63}$ from the fully relaxed bulk in order to avoid unrealistic strains in the surface calculations. Surface terminations were chosen to generate non-polar supercells (Figure 2), avoiding dipole effects under periodic boundary conditions. ${ }^{64}$ The $\{001\}$ and the $\{111\}$ surfaces are S-terminated, the $\{011\}$ is Fe-terminated, and the $\{100\}$ termination contains both $\mathrm{S}$ and $\mathrm{Fe}$ in the surface plane. The schematic representations of the relaxed surface structures are shown in Figure 2. The Fe sites on the $\{011\},\{100\}$, and $\{111\}$ surfaces are three-fold coordinated with sulfur compared to the tetrahedral coordination on the $\{001\}$ surface and in the bulk. Convergence tests with respect to slab thickness were performed such that surface energies were converged to within $0.01 \mathrm{~J} / \mathrm{m}^{2}$. The $\{001\}$ surface slab was constructed with two $\mathrm{FeS}$ unit layers (i.e., 6 atomic layers) whereas the $\{011\},\{100\}$, and $\{111\}$ surface slabs were made up of three $\mathrm{FeS}$ unit layers, consisting of 6,9 , and 9 atomic layers, respectively (side views of Figure 2). In each simulation cell, a vacuum region of $15 \AA$ was tested to be sufficient to avoid interactions between periodic slabs. The order of increasing surface energies, and therefore 

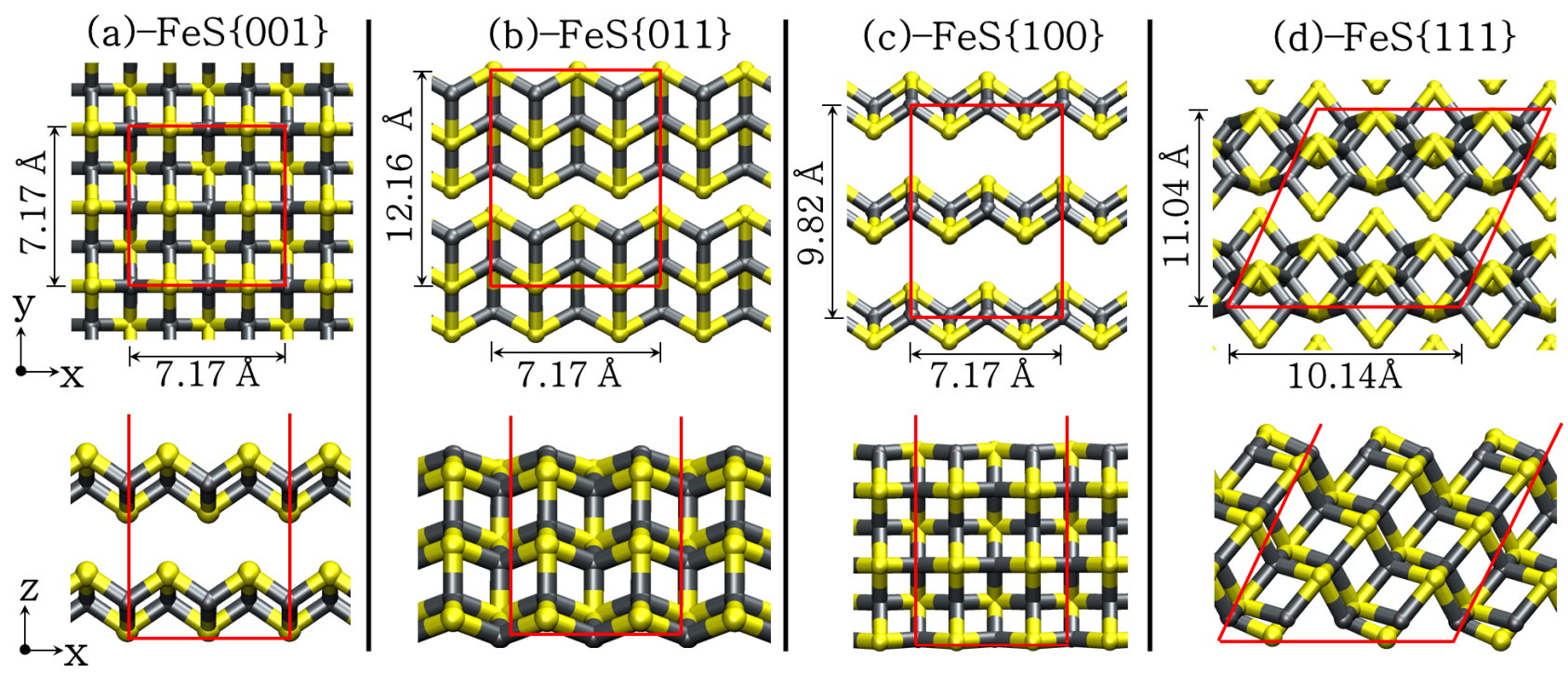

FIG. 2. Schematic illustration of the top (top row) and side (bottom row) views of the relaxed structures of the (a) $\{001\}$, (b) $\{011\}$, (c) $\{100\}$, and (d) $\{111\}$ surfaces of FeS. A $(2 \times 2)$ unit cell size used for the adsorption calculations is highlighted by dashed lines. (Colour scheme: $\mathrm{Fe}=$ grey and $\mathrm{S}=$ yellow.)

decreasing stability of the FeS surfaces, was determined to be $\{001\}<\{011\}<\{100\}<\{111\},{ }^{19}$ which is consistent with the results obtained from selected area electron diffraction (SAED) analyses of FeS nanocrystals. ${ }^{62}$ The $\{001\}$ surface was by far the most stable surface of FeS because its creation only involves breaking the weak vdW interactions between the sulfide layers, with negligible relaxation of the surface species. Consistent with its relative stability, the $\{001\}$ surface is the most highly expressed plane in the equilibrium morphology of $\mathrm{FeS}$, which grows in thin tabular crystals with the edges composed mainly of the $\{011\},\{100\}$, and $\{111\}$ planes. ${ }^{9,62}$ The relative stabilities and the structures of the different $\mathrm{FeS}$ surfaces may have important implications for their chemical reactivity towards adsorbing species.

In modelling the interactions of water and its dissociation products with the different $\mathrm{FeS}$ surfaces, the atoms of each adsorbate and the three topmost layers of the slab were allowed to relax unconstrainedly until residual forces on all atoms had reached less than $0.01 \mathrm{eV} / \AA$. The surface geometry optimizations were performed using $5 \times 5 \times 1 \mathrm{~K}$ points meshes. Bader charge analysis was carried out for all the adsorbate-substrate systems, using the code implemented by Henkelman and co-workers ${ }^{65}$ to quantify charge transfer between the surfaces and adsorbates. The evaluation of minimum-energy reaction paths (MEPs) and transition states (TSs) was performed using the climbing image nudged elastic band (CI-NEB) method. ${ }^{66,67}$ Typically, six images were produced between the states of reactant and product in each elementary process as the initial guesses for the reaction coordinates. The saddle point between the reactant and product is confirmed by vibrational frequency calculations, in which only one imaginary frequency is obtained corresponding to the reaction coordinate. The reaction energy $(\Delta E)$ is calculated as the total energy difference between the final state and the initial state, and the activation barrier $\left(E_{\mathrm{a}}\right)$ is defined as the total energy difference between the initial state and the saddle point.

\section{RESULTS AND DISCUSSION}

\section{A. $\mathrm{H}_{2} \mathrm{O}$ adsorption on $\mathrm{FeS}$ surfaces}

As a first step, active sites were investigated for the adsorption of the one water molecule per $(2 \times 2)$ simulation cell of the $\{001\},\{011\},\{100\}$, and $\{111\}$ surfaces, which have surface areas of $5.14 \mathrm{~nm}^{2}, 8.72 \mathrm{~nm}^{2}, 7.04 \mathrm{~nm}^{2}$, and $11.19 \mathrm{~nm}^{2}$, respectively (Figure 2). In order to interpret the adsorption cases explicitly and conveniently, a monolayer (ML) is defined as one water molecule for every surface cation site. Thus adsorption of a single water molecule on the $\{001\},\{011\},\{100\}$, and $\{111\}$ surfaces corresponds to the coverage of $1 / 8,1 / 4,1 / 4$, and $1 / 8 \mathrm{ML}$, respectively. The adsorption energy of water on the various FeS surfaces can be calculated using the equation

$$
E_{\text {ads }}=E_{\text {surface }+ \text { water }}-\left(E_{\text {surface }}+E_{\text {water }}\right),
$$

where $E_{\text {adsorbate/surface }}$ is the total energy of the adsorbatesubstrate system in the equilibrium state, $E_{\text {surface }}$ is the total energy of the substrate alone, and $E_{\text {adsorbate }}$ is the total energy of the isolated adsorbate. By this definition, a negative value of $E_{\text {ads }}$ indicates an exothermic and stable adsorption, whereas a positive value indicates an endothermic and unstable adsorption. Although different initial adsorption configurations and binding sites were explored for the individual chemical species that are involved in $\mathrm{H}_{2} \mathrm{O}$ dissociation on each surface, only the lowest-energy structures for each surface were characterised via vibrational frequency analysis and discussed in detail. In this work, all of the reported energies were corrected by the zero-point energy $(\triangle \mathrm{ZPE}){ }^{68}$ calculated as the difference between the $\mathrm{ZPE}$ correction for the adsorbate on the surface and in the gas phase, according to the equation as follows:

$$
\Delta \mathrm{ZPE}=\left(\sum_{i=1}^{3 n} \frac{h v_{i}}{2}\right)_{\text {surf }}-\left(\sum_{i=1}^{3 n} \frac{h v_{i}}{2}\right)_{\text {gas }},
$$


(a)- $\mathrm{FeS}\{001\}$

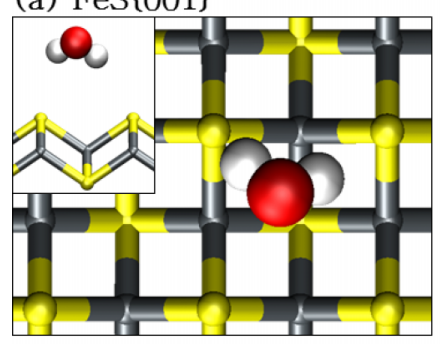

(c)-FeS $\{100\}$

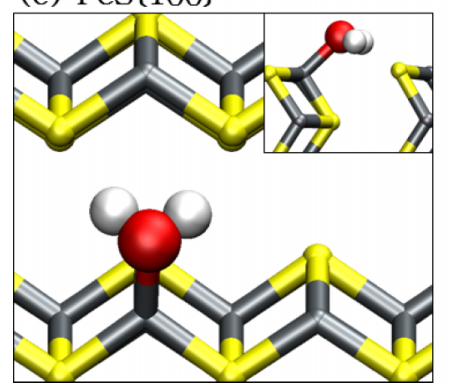

(b) $-\mathrm{FeS}\{011\}$

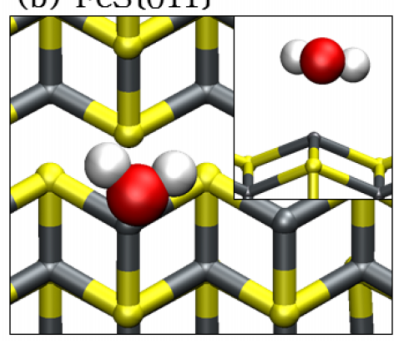

(d) $-\mathrm{FeS}\{111\}$

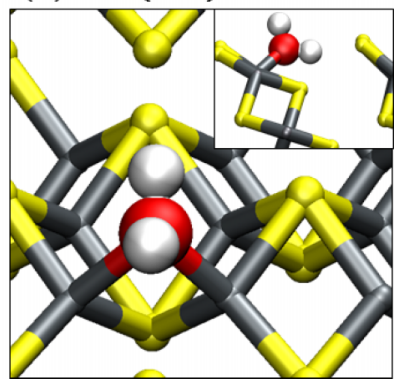

FIG. 3. The optimized structures of the most favorable binding conformations of $\mathrm{H}_{2} \mathrm{O}$ on (a) $\mathrm{FeS}\{001\}$, (b) $\mathrm{FeS}\{011\}$, (c) $\mathrm{FeS}\{100\}$, and (d) $\mathrm{FeS}\{111\}$ surfaces. The inserts represent the side views of the structures. (Colour scheme: $\mathrm{Fe}=$ grey, $\mathrm{S}=$ yellow, $\mathrm{O}=$ red and $\mathrm{H}=$ white.)

where $h$ is the Planck constant and $v_{i}$ are the vibrational frequencies.

The optimised adsorption geometries of water on the different FeS surfaces are shown in Figure 3, and the calculated adsorption energies, optimized geometry parameters, and vibrational frequencies are listed in Table I. On the $\mathrm{FeS}\{001\}$, we considered different high-symmetry sites and found that the water molecule interacts very weakly with the hydrogen atoms pointing toward surface sulfur atoms, ${ }^{74,75}$ releasing an adsorption energy of $0.15 \mathrm{eV}$. The contribution from the dispersion correction to this adsorption energy is $0.13 \mathrm{eV}$, which is about $87 \%$ of the total value, highlighting the importance of dispersion forces on stabilising the water molecule on the $\mathrm{FeS}\{001\}$ surfaces. The shortest S-H interatomic distance is calculated at $2.679 \AA$. Consistent with the weak interaction, we observe no significant changes in the geometrical parameters of the adsorbed water molecule compared to the gas phase (Table I). Compared to the $\{001\}$ surface, on the $\{011\},\{100\}$, and $\{111\}$ surfaces, the water molecule oriented itself with the $\mathrm{O}$ atom closest to the surface cation sites, thereby producing strong interactions. The adsorption energies and the corresponding dispersion

contributions $\left(E_{\mathrm{ads}}, E_{\mathrm{vdW}}\right)$, in absolute values, are calculated at $(0.63,0.10),(1.00,0.16)$, and $(1.50,0.20) \mathrm{eV}$ on the $\{011\},\{100\}$, and $\{111\}$ surfaces, respectively, indicating that the interaction of water is strongest at the $\{111\}$ surface and weakest on the $\{001\}$ surface. This order is consistent with the trend generally observed for the thermodynamic stabilities of the surfaces, where the less stable surfaces are more reactive towards adsorbing species. ${ }^{69}$ The $\mathrm{O}-\mathrm{H}$ bond lengths calculated for water on these surfaces (Table I) were slightly larger than that of a free $\mathrm{H}_{2} \mathrm{O}$ molecule $(0.972 \AA)$ in vacuum, indicating that the $\mathrm{O}-\mathrm{H}$ bonds are weakened when the molecule is adsorbed on the $\mathrm{FeS}$ $\{011\},\{100\}$, and $\{111\}$ surfaces, which was confirmed via our calculated $\mathrm{O}-\mathrm{H}$ bond stretching vibrational frequencies presented in Table I. The order of increasing lengths, and therefore decreasing strengths, of the $\mathrm{O}-\mathrm{H}_{1}$ bonds is $\{001\}$ $<\{011\}<\{100\}<\{111\}$, whereas for the $\mathrm{O}-\mathrm{H}_{2}$ bonds, it is $\{001\}<\{111\}<\{011\}<\{100\}$. Consistent with the fact that shorter (stronger) bonds have higher vibrational modes than longer (weaker) bonds, we found that the symmetric vibrational modes decrease with increasing $\mathrm{O}-\mathrm{H}_{1}$ bond lengths in the order $\{111\}<\{100\}<\{011\}<\{001\}$, whereas the asymmetric modes decrease with increasing $\mathrm{O}-\mathrm{H}_{2}$ bond lengths in the order $\{100\}<\{011\}<\{001\}<\{111\}$. The change in the vibrational modes and bond strengths is related to the electron density between the surface and the adsorbed water molecule (Figure 4), and therefore provides insight into the anisotropy on the different surfaces.

The electrostatic interactions between the $\mathrm{H}_{2} \mathrm{O}$ molecule and the different surfaces were further confirmed by Bader charge analysis. ${ }^{65}$ Charge analysis was focused on the atoms of the $\mathrm{H}_{2} \mathrm{O}$ molecule and the surface atoms nearest to the adsorption location. The $\mathrm{S}$ and $\mathrm{O}$ atoms in all systems had negative effective charges, while the $\mathrm{Fe}$ and $\mathrm{H}$ atoms had positive effective charges, which helps to explain the earlier noted repulsion between the $\mathrm{O}$ atom of the $\mathrm{H}_{2} \mathrm{O}$ molecule and $\mathrm{S}$ atoms of the $\{001\}$ surface, whereas surface $\mathrm{Fe}$ atoms attract the $\mathrm{O}$ atom. This is one reason why the $\{001\}$ surface does not strongly interact with $\mathrm{H}_{2} \mathrm{O}$ molecules as the layer of negatively charged $\mathrm{S}$ atoms shields the inner $\mathrm{Fe}$ atoms. In order to further study the interaction between the $\mathrm{H}_{2} \mathrm{O}$ molecule and various $\mathrm{FeS}$ surfaces and any possible charge transfer, we have plotted the charge density difference $\Delta \rho$ as shown in Figure 4. Here, $\Delta \rho=\rho$ (surface $\left.+\mathrm{H}_{2} \mathrm{O}\right)-\left(\rho(\right.$ surface $\left.)+\rho\left(\mathrm{H}_{2} \mathrm{O}\right)\right)$, where $\rho\left(\right.$ surface $\left.+\mathrm{H}_{2} \mathrm{O}\right)$ and $\rho$ (surface) are the charge densities of the surface with and without adsorbed $\mathrm{H}_{2} \mathrm{O}$, respectively, and $\rho\left(\mathrm{H}_{2} \mathrm{O}\right)$ is the charge

TABLE I. Molecular adsorption energies $\left(E_{\text {ads }}\right)$ and structural parameters of $\mathrm{H}_{2} \mathrm{O}$ on the $\{001\},\{011\},\{100\}$, and $\{111\}$ surfaces of FeS. $E_{\text {ads }}$ values in parenthesis include ZPE correction. $d_{\text {surf-ads }}$ is the shortest distance between any atom of the adsorbate(s) and any surface atom, $|q|$ is the absolute value of charge on the adsorbed species, and $v_{\mathrm{O}-\mathrm{H}}$ is the $\mathrm{O}-\mathrm{H}$ bond asymmetric and symmetric (bracket) stretching vibrational modes.

\begin{tabular}{lcccccc}
\hline \hline Surface & $E_{a d s}(\mathrm{eV})$ & $d\left(\mathrm{O}-\left(\mathrm{H}_{1}, \mathrm{H}_{2}\right)\right)(\AA)$ & ${ }^{\alpha} \mathrm{OHO}(\mathrm{deg})$ & $d($ surf-ads $)(\AA)$ & $|q|(e-)$ & $v(\mathrm{O}-\mathrm{H})\left(\mathrm{cm}^{-1}\right)$ \\
\hline $\mathrm{H}_{2} \mathrm{O}(\mathrm{g})$ & & $0.972,0.972$ & 104.7 & & & $3713(3623)$ \\
$\{001\}$ & $-0.17(-0.15)$ & $0.974,0.974$ & 104.0 & 4.158 & 0.00 & $3857(3695)$ \\
$\{011\}$ & $-0.68(-0.63)$ & $0.981,0.977$ & 105.3 & 2.185 & 0.01 & $3653(3555)$ \\
$\{100\}$ & $-1.10(-1.00)$ & $0.992,0.991$ & 101.9 & 2.092 & 0.03 & $3396(3292)$ \\
$\{111\}$ & $-1.58(-1.50)$ & $1.028,0.976$ & 107.7 & 2.197 & 0.07 & $3734(2647)$ \\
\hline \hline
\end{tabular}


(a) $-\mathrm{FeS}\{001\}$

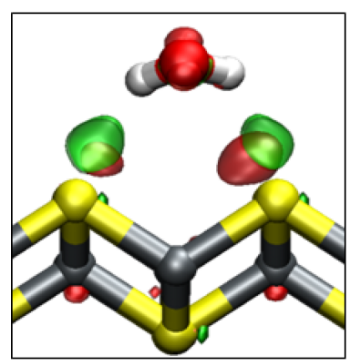

(c) $-\mathrm{FeS}\{100\}$

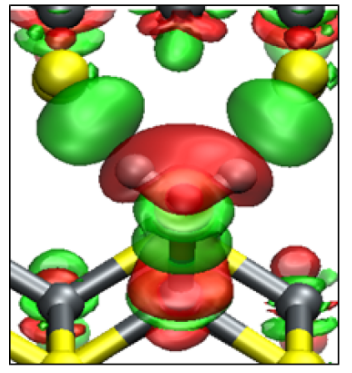

(b)-FeS\{011\}

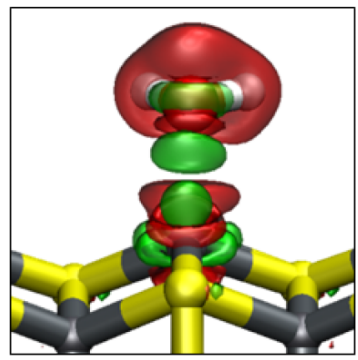

(d) $-\mathrm{FeS}\{111\}$

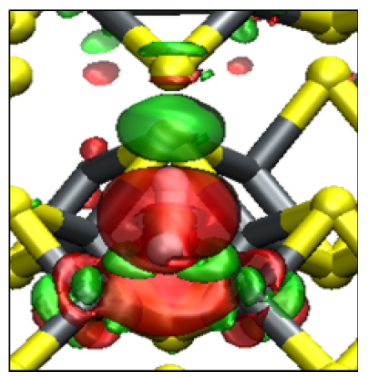

FIG. 4. Isosurfaces of the charge density difference $(\Delta \rho)$ for $\mathrm{H}_{2} \mathrm{O}$ molecule adsorbed on (a) $\mathrm{FeS}\{001\}$, (b) $\mathrm{FeS}\{011\}$, (c) $\mathrm{FeS}\{100\}$, and (d) $\mathrm{FeS}\{111\}$. The positive and negative isosurfaces are in green and red, indicating regions of charge gain and loss, respectively.

density of the isolated $\mathrm{H}_{2} \mathrm{O}$ molecule. The $\{011\},\{100\}$ and $\{111\}$ surfaces displayed a greater charge redistribution than the $\{001\}$ surface, and there appears to be a slight charge transfer to the $\mathrm{H}_{2} \mathrm{O}$ molecule, which ends up with a small negative overall charge $\left(0.01-0.04 e^{-}\right)$as shown in Table I. The large regions of charge loss between the $\mathrm{H}_{2} \mathrm{O}$ molecule and the $\mathrm{S}$ atoms for the $\{001\}$ surface points to the repulsion felt between the $\mathrm{O}$ and $\mathrm{S}$ atoms. On each of the $\{011\},\{100\}$, and $\{111\}$ surfaces, the charge is redistributed within the newly formed bond regions in the $\mathrm{FeS}-\mathrm{H}_{2} \mathrm{O}$ system, indicating a strong interaction between the $\mathrm{H}_{2} \mathrm{O}$ molecule and the surface Fe atoms.

\section{B. $\mathrm{H}_{2} \mathrm{O}$ dissociation on FeS surfaces}

The results presented above show that the $\mathrm{H}_{2} \mathrm{O}$ adsorption process itself results in $\mathrm{O}-\mathrm{H}$ bond stretching, suggesting that these molecular states are likely precursors for $\mathrm{H}_{2} \mathrm{O}$ dissociation. We now seek to determine how the differences in surface structures may dictate the reactivity of the system with respect to $\mathrm{H}_{2} \mathrm{O}$ dissociation $\left(\mathrm{H}_{2} \mathrm{O} \rightarrow \mathrm{OH}+\mathrm{H}\right)$. The main optimized structures of the initial predissociation state (IS), transition state (TS), and the final dissociated state (FS) and the calculated energy diagrams for the different surfaces are shown in Figures 5-8. When the water molecule is dissociated, the $\mathrm{OH}$ species interact preferably with the iron sites via the oxygen atom on all the surfaces considered except for the $\{001\}$ surface, with the $\mathrm{H}$ atom binding at sulfur or iron sites, depending on the surface (FS in Figures 5-8). We observed from our Bader population analyses that in contrast to the small net charge gained by molecular water, the dissociation products gain significant charge from the interacting surface species. At the $\mathrm{FeS}\{001\}$ surface, the $\mathrm{OH}$ species draws a

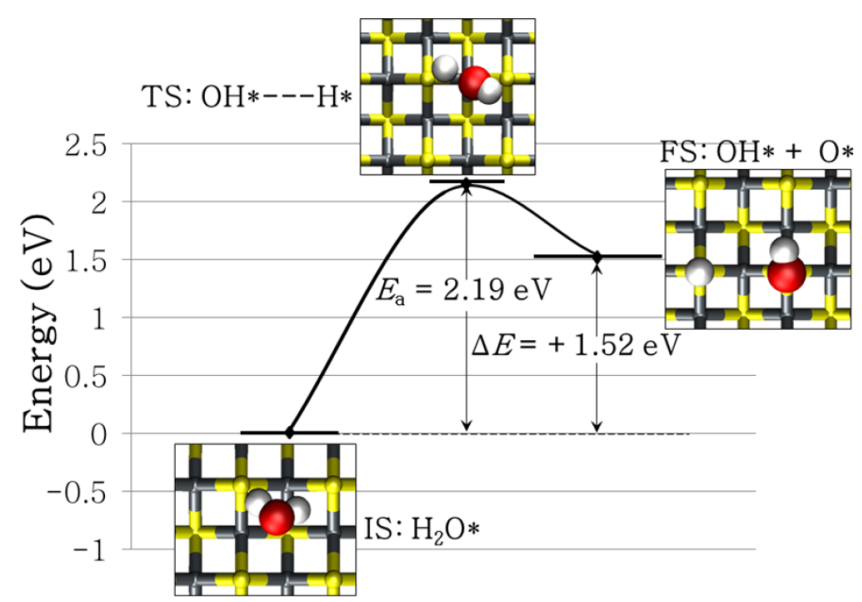

FIG. 5. Calculated reaction energy profile of $\mathrm{H}_{2} \mathrm{O}$ dissociation on the $\mathrm{FeS}\{001\}$ surface. The inserts show the structures of the initial (IS), transition (TS), and final (FS) states. The asterisks $(*)$ denote the adsorbed species.

charge of $1.02 e^{-}$from the interacting $\mathrm{S}$ ion, causing it to be significantly oxidized and positively charged $(+0.24 e-)$ compared to the negative charge of $-0.83 e-$ computed for the non-interacting surface $\mathrm{S}$ ions. The dissociated $\mathrm{H}$ atom on the other hand loses $0.06 e^{-}$to the surface $\mathrm{S}$ atom it is bound to. At the $\{011\},\{100\}$, and $\{111\}$ surfaces, we found that both dissociation products, $\mathrm{OH}$ and $\mathrm{H}$, gained a net charge from the interacting surface species; the assigned $(\mathrm{OH}, \mathrm{H})$ charges are $(0.51,0.22),(0.56,1.22)$, and $(0.62,1.26) e^{-}$, respectively. Further analysis reveals that the higher charge gained by the dissociated $\mathrm{H}$ species on the $\{100\}$ and $\{111\}$ surfaces causes significant oxidation of the interacting surface $\mathrm{S}$ atoms; they become positively charged $\left(+0.73 e^{-}\right.$on the $\{100\}$ and $+0.75 e^{-}$on the $\left.\{111\}\right)$ compared to the negative charge of $-0.83 e^{-}$computed for the non-interacting surface $S$ ions. These results suggest that the dissociation of water at the $\{100\}$ and $\{111\}$ may lead to the formation of surface-bound $\mathrm{OH}^{-}$and $\mathrm{SH}^{-}$species. The $\mathrm{SH}^{-}$species thus formed could serve as a precursor to the formation of $-\mathrm{SH}_{2}$ upon further proton attachment and acts as the starting point of surface oxidation. ${ }^{76}$

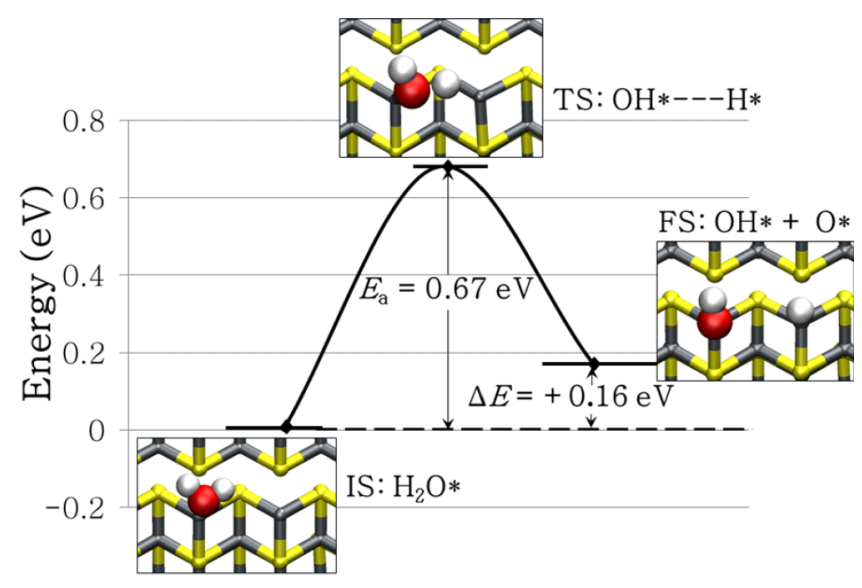

FIG. 6. Calculated reaction energy profile of $\mathrm{H}_{2} \mathrm{O}$ dissociation on the FeS $\{011\}$ surface. The inserts show the structures of the initial (IS), transition (TS), and final (FS) states. The asterisks (*) denote the adsorbed species. 


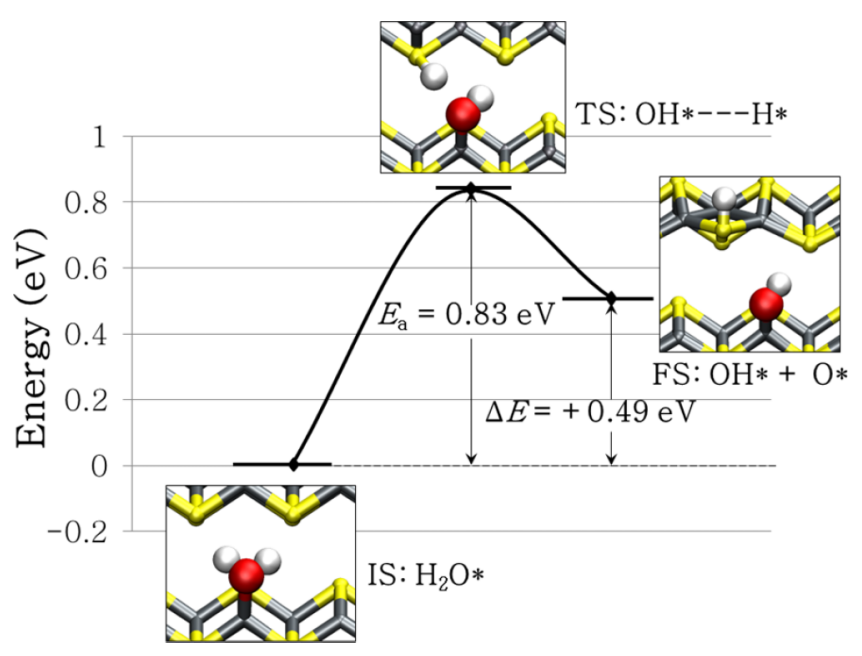

FIG. 7. Calculated reaction energy profile of $\mathrm{H}_{2} \mathrm{O}$ dissociation on the $\mathrm{FeS}\{100\}$ surface. The inserts show the structures of the initial (IS), transition (TS), and final (FS) states. The asterisks $(*)$ denote the adsorbed species.

Relative to the predissociation state on the $\{001\}$ surface, the dissociation of water is found to be a highly endothermic process with calculated thermochemical energy of $+1.52 \mathrm{eV}$ and a high activation energy barrier of $2.19 \mathrm{eV}$ to be overcome. The high activation barrier and the endothermic reaction energy calculated on the FeS $\{001\}$ surface are similar to those previously calculated on the $\mathrm{MoS}_{2} \mathrm{~S} 100$-edge at $2.31 \mathrm{eV}$ and $1.40 \mathrm{eV}$, respectively. ${ }^{35}$ The calculated reaction energies on the other surfaces show that the water dissociation reaction is slightly exothermic $(\Delta \mathrm{E}=-0.10 \mathrm{eV})$ on the $\{111\}$, slightly endothermic $(\Delta \mathrm{E}=+0.16 \mathrm{eV})$ on the $\{011\}$, and endothermic $(\Delta \mathrm{E}=+0.49 \mathrm{eV})$ on the $\{100\}$ surfaces. The activation energy barriers calculated on the $\{011\},\{100\}$, and $\{111\}$ surfaces were significantly lower than for water dissociation on the $\{001\}$ surface; they are calculated at $0.67,0.83$, and $0.62 \mathrm{eV}$, respectively. The lowest activation energy barrier of $0.62 \mathrm{eV}$ calculated on the FeS $\{111\}$ surface compares with the energy barrier of $0.54 \mathrm{eV}$ calculated at the Mo-edge of $\mathrm{MoS}_{2}{ }^{35}$

Whether water will desorb or will dissociate on the various FeS surfaces can be ascertained from comparison

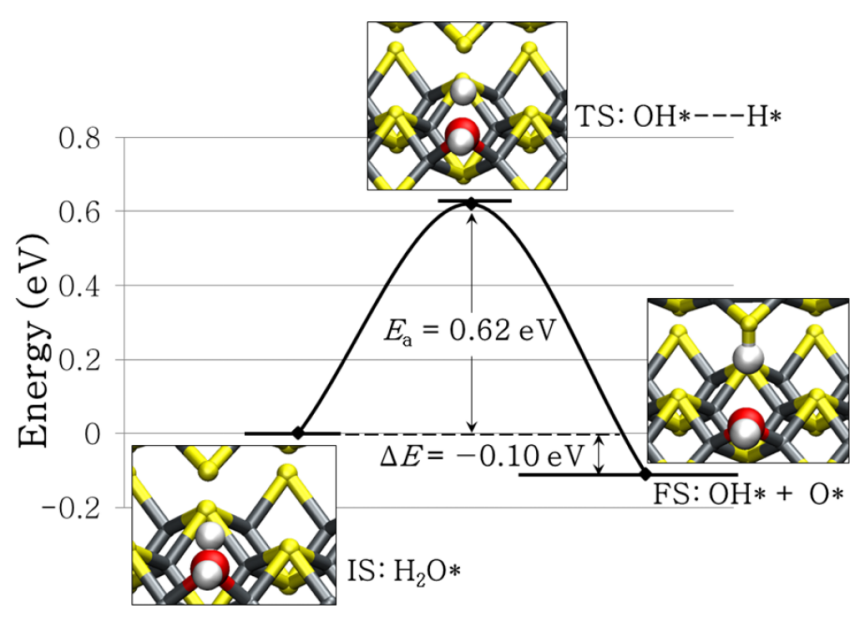

FIG. 8. Calculated reaction energy profile of $\mathrm{H}_{2} \mathrm{O}$ dissociation on the FeS $\{111\}$ surface. The inserts show the structures of the initial (IS), transition (TS), and final (FS) states. The asterisks (*) denote the adsorbed species. of the activation energy barriers for water dissociation on the four surfaces considered (Figures 5-8) and of the water adsorption energies on the corresponding surfaces (Table I). The adsorption energy of the water molecule on the FeS $\{001\}$ and $\{011\}$ surfaces is clearly smaller in absolute value, particularly on the $\{001\}$ surface, than the energy barrier required for water dissociation and dissociation is hence not expected on the FeS $\{001\}$ and $\{011\}$ surfaces without the presence of promoters, e.g., $\mathrm{OH}$ and $\mathrm{O}$ species, on the surface. It is therefore expected that water will desorb from the FeS $\{001\}$ and $\{011\}$ surfaces, as is found for other iron sulfides. ${ }^{43,46}$ However, a different picture emerges for the adsorption and dissociation of water on the FeS $\{100\}$ and \{111\} surfaces. There, the absolute values of the adsorption energies are larger, i.e., by 0.17 and $0.88 \mathrm{eV}$ on the $\{100\}$ and $\{111\}$ surfaces, respectively, than the energy required to dissociate the molecule into the $\mathrm{OH}$ and $\mathrm{H}$ fragments; hence, water dissociation is suggested to occur on FeS surfaces with these Miller indices. However, the positive reaction energy $(\Delta \mathrm{E}=+0.49 \mathrm{eV})$ for water dissociation on the FeS $\{100\}$ surface points to unfavourable thermodynamics, which therefore suggest that water dissociation might be difficult to obtain at low temperatures. The negative reaction energy $(\Delta \mathrm{E}=-0.10 \mathrm{eV})$ for water dissociation on the $\{111\}$ shows the thermodynamics to be favourable, whereas the low activation barrier points to accessible kinetics. Water dissociation is therefore suggested to occur primarily on the FeS $\{111\}$ surface, in tandem with the superior capacity for water adsorption on this surface.

Compared with earlier DFT results of water dissociation on violarite $\left(\mathrm{FeNi}_{2} \mathrm{~S}_{4}\right)$ surfaces, we found that the calculated activation energy barriers on the FeS $\{011\},\{100\}$, and $\{111\}$ surfaces are all lower than those calculated at $1.28 \mathrm{eV}$ for $\mathrm{FeNi}_{2} \mathrm{~S}_{4}\{001\}$ and $1.11 \mathrm{eV}$ for $\mathrm{FeNi}_{2} \mathrm{~S}_{4}\{011\} .{ }^{46}$ They can also be compared to the activation energy barrier of $0.71 \mathrm{eV}$ calculated for water dissociation on iron oxide $\mathrm{Fe}_{3} \mathrm{O}_{4}\{111\} .^{70}$ While activation at low coverage was required for water on iron oxide surfaces, at high coverage water was shown to dissociate readily, due to hydrogen bonding effects, suggesting that pre-adsorbed water has a strong synergistic effect on the dissociative chemisorption of another water molecule. ${ }^{70-72}$ However, the size of the super cells used in this work results in a distance of at least $5 \AA$ between the hydrogen and oxygen of neighbouring water molecules (i.e., between periodic images) on each surface. This distance is much larger than the typical hydrogen-bond length in water, which is $1.97 \AA .{ }^{73}$ Hence, hydrogen-bonding is not expected to be important in the models studied here.

\section{SUMMARY AND CONCLUSIONS}

Water adsorption and dissociation were investigated on the low-index $\{001\},\{011\},\{100\}$, and $\{111\}$ surfaces of $\mathrm{FeS}$, using density functional theory calculations, corrected for long-range dispersion interactions (DFT-D2). We have shown from our calculated adsorption energies that water and its dissociation products adsorb most strongly onto the least stable FeS $\{111\}$ surface and most weakly onto the most stable 
FeS $\{001\}$ surface; the adsorption energy for $\mathrm{H}_{2} \mathrm{O}$ decreases in the order $\operatorname{FeS}\{111\}>\operatorname{FeS}\{100\}>\operatorname{FeS}\{011\}>\operatorname{FeS}\{001\}$. An inspection of the reaction paths for $\mathrm{H}_{2} \mathrm{O}$ dissociation on the various $\mathrm{FeS}$ surfaces shows that the lowest activation barrier and most favourable thermodynamics are found on $\{111\}$ surface. Water dissociation is therefore likely to occur only on the $\{111\}$ surfaces, whereas on the other surfaces, it will remain adsorbed molecularly. Future works will investigate higher water loadings on the surfaces to study any synergistic effects on pre-adsorbed water on the dissociation process.

\section{ACKNOWLEDGMENTS}

We acknowledge the Netherlands Foundation for Fundamental Research on Matter (FOM) for funding (Grant No. 13CO26-2). This work made use of the facilities of ARCHER (http://www.archer.ac.uk), the UK's national supercomputing service, via our membership of the UK's HEC Materials Chemistry Consortium, which is funded by EPSRC (No. EP/L000202).

${ }^{1}$ P. A. Thiel and T. E. Madey, Surf. Sci. Rep. 7, 211 (1987).

${ }^{2}$ M. A. Henderson, Surf. Sci. Rep. 46, 1 (2002).

${ }^{3}$ S. Meng, E. G. Wang, and S. Gao, Phys. Rev. B 69, 195404 (2004).

${ }^{4}$ M. Pozzo, G. Carlini, R. Rosei, and D. Alfè, J. Chem. Phys. 126, 164706 (2007).

${ }^{5}$ C.-H. Lin, C.-L. Chen, and J.-H. Wang, J. Phys. Chem. C 115, 18582 (2011).

${ }^{6}$ X. Wang, H. Huang, B. Liang, Z. Liu, D. Chen, and G. Shen, Crit. Rev. Solid State Mater. Sci. 38, 57 (2013).

${ }^{7}$ M. Chhowalla, H. S. Shin, G. Eda, L.-J. Li, K. P. Loh, and H. Zhang, Nat. Chem. 5, 263 (2013).

${ }^{8}$ A. Kirkeminde, R. Scott, and S. Ren, Nanoscale 4, 7649 (2012).

${ }^{9}$ A. L. Abdelhady, M. A. Malik, P. O'Brien, and F. Tuna, J. Phys. Chem. C 116, 2253 (2012)

${ }^{10}$ M. Akhtar, J. Akhter, M. A. Malik, P. O’Brien, F. Tuna, J. Raftery, and M. Helliwell, J. Mater. Chem. 21, 9737 (2011).

${ }^{11}$ C. Steinhagen, T. B. Harvey, C. J. Stolle, J. Harris, and B. A. Korgel, J. Phys. Chem. Lett. 3, 2352 (2012).

${ }^{12}$ C. W. Lin, D. Y. Wang, Y. T. Wang, C. C. Chen, Y. J. Yang, and Y. F. Chen, Sol. Energy Mater. Sol. Cells 95, 1107 (2011).

${ }^{13}$ Y. Bi, Y. Yuan, C. L. Exstrom, S. A. Darveau, and J. Huang, Nano Lett. 11, 4953 (2011).

${ }^{14}$ B. Wu, H. Song, J. Zhou, and X. Chen, Chem. Commun. 47, 8653 (2011).

${ }^{15}$ Y. Yamaguchi, T. Takeuchi, H. Sakaebe, H. Kageyama, H. Senoh, T. Sakai, and K. Tatsumi, J. Electrochem. Soc. 157, A630 (2010).

${ }^{16}$ A. Paolella, C. George, M. Povia, Y. Zhang, R. Krahne, M. Gich, A. Genovese, A. Falqui, M. Longobardi, P. Guardia, T. Pellegrino, and L. Manna, Chem. Mater. 23, 3762 (2011).

${ }^{17}$ M. Feng, Y. Lu, Y. Yang, M. Zhang, Y.-J. Xu, H.-L. Gao, L. Dong, W.-P. Xu, and S.-H. Yu, Sci. Rep. 3, 2994 (2013).

${ }^{18}$ A. Roldan, N. Hollingsworth, A. Roffey, H.-U. Islam, J. B. M. Goodall, C. R. A. Catlow, J. A. Darr, W. Bras, G. Sankar, K. B. Holt, G. Hogarth, and N. H. de Leeuw, Chem. Commun. 51, 7501 (2015).

${ }^{19}$ N. Y. Dzade, A. Roldan, and N. H. de Leeuw, Phys. Chem. Chem. Phys. 16, 15444 (2014).

${ }^{20}$ C.-H. Lai, M.-Y. Lu, and L.-J. Chen, J. Mater. Chem. 22, 19 (2012).

${ }^{21}$ J. B. Varley, H. A. Hansen, N. L. Ammitzbøll, L. C. Grabow, A. A. Peterson, J. Rossmeisl, and J. K. Nørskov, ACS Catal. 3, 2640 (2013).

${ }^{22}$ M. J. Russell and A. J. Hall, J. Geol. Soc. London 154, 377 (1997).

${ }^{23}$ W. Martin, J. Baross, D. Kelley, and M. J. Russell, Nat. Rev. Microbiol. 6, 805 (2008).

${ }^{24}$ G. D. Cody, Annu. Rev. Earth Planet. Sci. 32, 569 (2008).

${ }^{25}$ C. Huber and G. Wächtershäuser, Science 276, 245 (1997).

${ }^{26} \mathrm{G}$. Wächtershäuser, Biophys. Mol. Biol. 58, 85 (1992).

${ }^{27}$ A. R. Lennie, S. A. T. Redfern, P. F. Schofield, and D. J. Vaughan, Mineral. Mag. 59, 677 (1995).

${ }^{28}$ R. A. Berner, Science 137, 669 (1962).
${ }^{29}$ D. J. Vaughan and J. R. Craig, Mineral Chemistry of Metal Sulfides (Cambridge University Press, New York, 1978).

${ }^{30}$ P. G. Moses, B. Hinnemann, H. Topsøe, and J. K. Nørskov, J. Catal. 248, 188 (2007).

${ }^{31}$ T. Wang, D. Gao, J. Zhuo, Z. Zhu, P. Papakonstantinou, Y. Li, and M. Li, Chem. Eur. J. 19, 11939 (2013).

${ }^{32}$ T. F. Jaramillo, K. P. Jørgensen, J. Bonde, J. H. Nielsen, S. Horch, and I. Chorkendorff, Science 317, 100 (2007).

${ }^{33}$ H. I. Karunadasa, E. Montalvo, Y. Sun, M. Majda, J. R. Long, and C. J. Chang, Science 335, 698 (2012).

${ }^{34}$ B. Hinnemann, P. G. Moses, J. Bonde, K. P. Jørgensen, J. H. Nielsen, S. Horch, I. Chorkendorff, and J. K. Nørskov, J. Am. Chem. Soc. 127, 5308 (2005).

${ }^{35}$ K. K. Ghuman, S. Yadav, and C. V. Singh, J. Phys. Chem. C 119, 6518 (2015).

${ }^{36}$ A. P. Chandra and A. R. Gerson, Surf. Sci. Rep. 65, 293 (2010).

${ }^{37}$ S. Boursiquot, M. Mullet, M. Abdelmoula, J.-M. Génin, and J.-J. Ehrhardt, Phys. Chem. Miner. 28, 600 (2001).

${ }^{38}$ K. M. Rosso, U. Becker, and M. F. Hochella, Am. Mineral. 84, 1549 (1999).

${ }^{39}$ H. W. Nesbitt and I. J. Muir, Geochim. Cosmochim. Acta 58, 4667 (1994).

${ }^{40}$ J. M. Guevremont, D. R. Strongin, and M. A. A. Schoonen, Surf. Sci. 391, 109 (1997).

${ }^{41}$ J. M. Guevremont, D. R. Strongin, and M. A. A. Schoonen, Langmuir 14, 1361 (1998).

${ }^{42}$ J. M. Guevremont, D. R. Strongin, and M. A. A. Schoonen, Am. Mineral. 83, 1246 (1998).

${ }^{43}$ A. Stirling, M. Bernasconi, and M. Parrinello, J. Chem. Phys. 118, 8917 (2003).

${ }^{44}$ P. H.-L. Sit, M. H. Cohen, and A. Selloni, J. Phys. Chem. Lett. 3, 2409 (2012).

${ }^{45}$ C. Zhao, J. Chen, B. Wu, and X. Long, Trans. Nonferrous Met. Soc. China 24, 491 (2014).

${ }^{46}$ S. Haider, A. Roldan, and N. H. de Leeuw, J. Phys. Chem. C 118, 1958 (2014).

${ }^{47}$ G. Kresse and J. Hafner, Phys. Rev. B 48, 13115 (1993).

${ }^{48}$ G. Kresse and J. Furthmüller, Phys. Rev. B 54, 11169 (1996).

${ }^{49}$ G. Kresse and J. Furthmüller, Comput. Mater. Sci. 6, 15 (1996).

${ }^{50}$ P. E. Blöchl, Phys. Rev. B 50, 17953 (1994).

${ }^{51}$ G. Kresse and D. Joubert, Phys. Rev. B 59, 1758 (1999).

${ }^{52}$ J. P. Perdew and A. Zunger, Phys. Rev. B 23, 5048 (1981).

${ }^{53}$ J. P. Perdew, J. A. Chevary, S. H. Vosko, K. A. Jackson, M. R. Pederson, D. J. Singh, and C. Fiolhais, Phys. Rev. B 46, 6671 (1992).

${ }^{54}$ N. Y. Dzade, A. Roldan, and N. H. de Leeuw, J. Chem. Phys. 139, 124708 (2013).

${ }^{55}$ S. Grimme, J. Comput. Chem. 27, 1787 (2006).

${ }^{56}$ H. J. Monkhorst and J. D. Pack, Phys. Rev. B 13, 5188 (1976).

${ }^{57}$ A. J. Devey, R. Grau-Crespo, and N. H. de Leeuw, J. Phys. Chem. C 112, 10960 (2008).

${ }^{58}$ A. Subedi, L. J. Zhang, D. J. Singh, and M. H. Du, Phys. Rev. B 78, 134514 (2008).

${ }^{59}$ J. Brgoch and G. J. Miller, J. Phys. Chem. A 116, 2234 (2012).

${ }^{60}$ K. D. Kwon, K. Refson, S. Bone, R. Qiao, W. Yang, Z. Liu, and G. Sposito, Phys. Rev. B 83, 064402 (2011).

${ }^{61}$ D. J. Vaughan and M. S. Ridout, J. Inorg. Nucl. Chem. 33, 741 (1971).

${ }^{62}$ H. Ohfuji and D. Rickard, Earth Planet. Sci. Lett. 241, 227 (2006).

${ }^{63}$ G. W. Watson, E. T. Kelsey, N. H. de Leeuw, D. J. Harris, and S. C. Parker, J. Chem. Soc., Faraday Trans. 92, 433 (1996).

${ }^{64}$ P. W. Tasker, J. Phys. C: Solid State Phys. 12, 4977 (1979).

${ }^{65}$ G. Henkelman, A. Arnaldsson, and H. Jonsson, Comput. Mater. Sci. 36, 354 (2006)

${ }^{66}$ G. Mills, H. Jónsson, and G. K. Schenter, Surf. Sci. 324, 305 (1995).

${ }^{67}$ A. Ulitsky and R. Elber, J. Chem. Phys. 92, 1510 (1990).

${ }^{68}$ H. Kragh, Arch. Hist. Exact Sci. 66, 199 (2012).

${ }^{69}$ N. H. de Leeuw and J. A. L. Rabone, CrystEngComm 9, 1178 (2007).

${ }^{70}$ C. G. Zhou, Q. F. Zhang, L. Chen, B. Han, G. Ni, J. P. Wu, D. Garg, and H. S. Cheng, J. Phys. Chem. C 114, 21405 (2010).

${ }^{71}$ R. S. Cutting, C. A. Muryn, D. J. Vaughan, and G. Thornton, Surf. Sci. 602, 1155 (2008).

${ }^{72}$ T. Kendelewicz, P. Liu, C. S. Doyle, G. E. Brown, E. J. Nelson, and S. A. Chambers, Surf. Sci. 453, 32 (2000).

${ }^{73}$ M. Yang, S. S. Stipp, and J. Harding, Cryst. Growth Des. 8, 4066 (2008).

${ }^{74}$ U. Terranova and N. H. de Leeuw, Theor. Chem. Acc. 135, 46 (2016).

${ }^{75}$ U. Terranova and N. H. de Leeuw, J. Chem. Phys. 144, 094706 (2016).

${ }^{76}$ D. Santos-Carballal, A. Roldan, and N. H. de Leeuw, "Early oxidation processes on the greigite $\mathrm{Fe}_{3} \mathrm{~S}_{4}$ (001) surface by water: A density functional theory study," J. Phys. Chem. C (published online 2016). 